\title{
Cyclic Guanosine Monophosphate Is the Mediator of Platelet-activating Factor Inhibition on Transport by the Mouse Kidney Thick Ascending Limb
}

\author{
Françoise Néant, Martine Imbert-Teboul,* and Claire Bailly \\ Laboratoire de Physiologie Rénale, Faculté Xavier Bichat, Université Paris 7, INSERM U 251, 75018 Paris, France; and *Laboratoire \\ de Physiologie Cellulaire, Collège de France, 75005 Paris, France
}

\begin{abstract}
Since we have previously shown a direct inhibitory effect of platelet-activating factor (PAF) on $\mathrm{Cl}$ reabsorption in the medullary thick ascending limb of Henle's loop (TAL), the aim of this study was to extend this effect to the whole TAL and to further investigate the signaling pathway involved. In microperfused cortical TALs, PAF significantly decreased $\mathrm{Cl}$ reabsorption by $50.3 \pm 6.5 \%$. On the one hand, this effect was not modified in the presence of staurosporine and was not mimicked by phorbol ester; chelating cytosolic Ca by BAPTA/AM failed to suppress the inhibitory effect of PAF on Cl reabsorption; moreover, no significant increase in intracellular Ca concentration could be observed in the presence of PAF on isolated tubules. On the other hand, 8-bromo cyclic GMP mimicked the PAF effect on $\mathrm{Cl}$ reabsorption and prevented a further effect of this agent; the PAF effect was significantly reduced by $\mathrm{H}-8$, a cyclic GMP-dependent protein kinase inhibitor; in medullary TALs, PAF significantly increased by twofold cyclic GMP content, an effect inhibited by the PAF antagonist BN 50730, whereas PAF did not significantly modify CAMP content in basal or stimulated conditions. Finally, inhibition of nitric oxide production by NAME or NMMA failed to prevent the effect of PAF on $\mathrm{Cl}$ reabsorption.

It is concluded that the PAF-induced inhibition of $\mathrm{Cl}$ reabsorption in the TAL was mediated by cyclic GMP, likely independent of a nitric oxide synthesis. (J. Clin. Invest. 1994. 94:1156-1162.) Key words: protein kinase $\mathrm{C} \cdot$ protein kinase - calcium - adenosine cyclic monophosphate • nitric oxide
\end{abstract}

\section{Introduction}

Platelet-activating factor (PAF) ${ }^{1}$ (1-O-alkyl-2-acetyl-sn-glycerol-3phosphocholine) is a ubiquitous autacoid that is involved in many

Part of this work was presented at the 26th meeting of the American Society of Nephrology (1993. J. Am. Soc. Nephrol. 4:450) in Boston, MA on 16-17 November 1993.

Address correspondence to Claire Bailly, Collège de France, Laboratorie de Physiologie Cellulaire, 11, Place Marcelin Berthelot, 75005 Paris, France.

Received for publication 26 January 1994 and in revised form 13 May 1994.

1. Abbreviations used in this paper: $[\mathrm{Ca}]_{\mathrm{i}}$, intracellular calcium concentration; cTAL, cortical thick ascending limb of Henle's loop; $\mathrm{J}_{\mathrm{Cl}}$, net chloride flux; mTAL, medullary thick ascending limb of Henle's loop; NAME, $N^{6}$. nitro-L-arginine methyl ester; NMMA, $N$ mono methyl arginine; NO, nitric oxide; PAF, platelet-activating factor; $V$, tubular flow rate.

J. Clin. Invest.

(c) The American Society for Clinical Investigation, Inc. 0021-9738/94/09/1156/07 \$2.00

Volume 94, September 1994, 1156-1162 pathophysiological events, among which are inflammation and anaphylactic reaction (1). In the kidney, it was established that PAF decreased the sodium chloride transport rate in the medullary thick ascending limb of Henle's loop (mTAL) by a dual manner: first by direct inhibition of the reabsorptive function of the MTAL, as demonstrated in our laboratory on isolated tubules (2); and second by decreasing the solute delivery to the MTAL, since PAF was shown to induce a decline of the glomerular filtration rate (3). These results, combined with the demonstration by Brezis et al. (4) that decreasing the reabsorptive function of the mTAL prevented the epithelium from the damages occurring during hypoxia, allowed us to postulate that PAF may play a role in the preservation of the cell integrity during renal injury (2).

It is known that the action of PAF on its target cells involves multiple signaling pathways among which are stimulation of tyrosine kinase, stimulation of phospholipase $\mathrm{A}_{2}, \mathrm{C}$, or $\mathrm{D}$, and inhibition of adenylate-cyclase (5). In the glomerulus, it has been reported extensively that PAF increased prostaglandin production via a calcium-mediated stimulation of phospholipase $A_{2}$ (3). However, other signaling pathways can be involved in that structure, especially in the glomerular mesangial cells (6). At variance with those reported for the glomerulus, the results obtained from the mTAL indicated that the PAF-induced net chloride flux $\left(\mathrm{J}_{\mathrm{Cl}}\right)$ inhibition did not result from phospholipase $A_{2}$ activation, neither was it mediated by adenosine (2). The effect of PAF on mTAL was antagonized by BN 50730, a result in accordance with the recent localization of PAF receptors in the cortical and medullary parts of the kidney (7).

The aim of the present study was to further investigate the mechanism of action underlying the inhibitory effect of PAF on the TAL reabsorptive function. TAL is involved in two main reabsorptive functions which are sodium chloride reabsorption, contributing to the generation of the corticopapillary gradient, and the reabsorption of the bulk of the filtered calcium and magnesium. Since chloride transport has been shown to be closely correlated to sodium transport as well as to the passive reabsorption of the divalent cations $(8,9), J_{\mathrm{Cl}}$, determined on microperfused tubules, was used as the representative parameter of the TAL function. The fact that, in the present study, the inhibitory effect of PAF on $\mathrm{J}_{\mathrm{Cl}}$ was found to be similar in the cortical TAL (cTAL) and in the MTAL allowed us to investigate the mechanism of action involved in this effect on either segment. The results here obtained showed that the inhibitory effect of PAF on $\mathrm{J}_{\mathrm{Cl}}(a)$ did not involve protein kinase $\mathrm{C}$ activation; (b) was not associated with any increase in intracellular calcium concentration $\left([\mathrm{Ca}]_{\mathrm{i}}\right) ;(c)$ was independent of cyclic AMP content modifications; but ( $d$ ) was mediated by cyclic GMP, independently of NO production. This study thus brings the first indication that PAF can directly stimulate the cyclic GMP pathway and underlines that, in the kidney, the PAF signaling pathways are different for the glomerulus and for the TAL.

\section{Methods}

Microperfusion experiments. cTALs (length $=459 \pm 18 \mu \mathrm{m}, n=73$ ) were microperfused in vitro following the technique first described by 
Burg et al. (10) and usually used in our laboratory. Briefly, male Swiss white mice, 18-20 g body wt, were killed by cervical dislocation and exsanguinated. Coronal slices were then cut from both kidneys and were immersed immediately in a cold perfusing solution (see composition detailed below) in which $0.4 \%$ bovine serum albumin was added. The cTALs were then transferred to a Lucite chamber in which the bath, thermostatically maintained at $36 \pm 0.1^{\circ} \mathrm{C}$, was flowing continuously at about $5 \mathrm{ml} / \mathrm{min}$.

Each perfused tubule was allowed to equilibrate during $1 \mathrm{~h}$. After equilibration, a 30-min control period was followed by one or two 30min experimental periods, during which the luminal fluid was collected every $10 \mathrm{~min}$. Between each period, $10 \mathrm{~min}$ was allowed for equilibration. All the tested agents were added into the bath, either since the beginning of the control period or during the experimental period, as mentioned in the text. When the tubules were loaded with BAPTA/AM (acetoxymethyl ester), the perfused tubules were incubated $30 \mathrm{~min}$ in the dark at room temperature, in the bathing solution containing $10^{-5}$ M BAPTA/AM in dimethylsulfoxide (final dilution 3,000 vol/vol). This incubation solution was then washed out and replaced by the flowing bathing solution before the beginning of the control period.

The composition of the perfusing solution was as follows (mM): $\mathrm{NaCl} 147, \mathrm{MgCl}_{2} 2, \mathrm{CaCl}_{2} 1, \mathrm{KCl} 2$, urea 10, Hepes 10. The composition of the bathing solution was similar, except for a lower $\mathrm{NaCl}$ concentration, $142 \mathrm{mM}$, because of the addition of glucose $(5 \mathrm{mM})$ and $\mathrm{Na}$ acetate $(5 \mathrm{mM})$. All the solutions were adjusted to 300 mosmol $\mathrm{H}_{2} \mathrm{O}$ with urea and to $\mathrm{pH} 7.39-7.42$.

In the collected fluid and perfusate, chloride concentration $\left(\mathrm{C}_{\mathrm{c}}\right.$ and $\mathrm{C}_{\mathrm{p}}$, respectively) was determined by microelectrometric titration (11). The tubular flow rate $(V)$ was calculated from the volume of the collected sample, assuming that water reabsorption was negligible in the TAL (12). The net chloride reabsorption was calculated as $\mathrm{J}_{\mathrm{Cl}}=\left(\mathrm{C}_{\mathrm{c}}-\mathrm{C}_{\mathrm{p}}\right)$ $\times V$. Since, in the CTAL, no evidence was brought that the chloride reabsorption was proportional to the tubular length when the chloride concentration decreased, and because the length of the perfused segments was fairly similar from one experiment to another, the net fluxes were not monitored by this parameter.

Data from the three collections of each 30 -min period were pooled and considered as one point. Values were expressed as means \pm SE. Statistical significance was evaluated within each series by the paired Student's $t$ test and between series by the one-way analysis of variance followed by the Fisher's least significant difference test.

Determination of $[\mathrm{Ca}]_{i}$. Experiments were carried out on isolated tubules, according to the technique already described (13). Briefly, tubules were microdissected from 11 male Swiss white mice, $18-20 \mathrm{~g}$ body wt, according to the protocol described above for microperfusion experiments. cTALs $(n=11)$ were harvested from the cortex of mouse kidney. Each tubule was then transferred on a slide where it was loaded for $1 \mathrm{~h}$ at room temperature in the dark, with a solution containing fura2/AM (acetomethoxy ester, $10^{-5} \mathrm{M}$ ) in dimethyl sulfoxide (final dilution $500 \mathrm{vol} / \mathrm{vol}$ ). Each fura-2-loaded tubule was then transferred to a Lucite chamber and superfused at $37^{\circ} \mathrm{C}$ with a bath continuously flowing at a rate of $10-12 \mathrm{ml} / \mathrm{min}$, so that full equilibrium concentration in the chamber was achieved in $\sim 15-20 \mathrm{~s}$. For each tubule, measurements of fura-2 fluorescence were carried out after a 5-10-min equilibration period. The composition of the bathing solution was as follows ( $\mathrm{mM}$ ): $\mathrm{NaCl} 150, \mathrm{KCl} 1, \mathrm{KHCO}_{3} 4, \mathrm{Na}_{2} \mathrm{HPO}_{4} 0.33, \mathrm{NaH}_{2} \mathrm{PO}_{4} 0.44, \mathrm{MgCl}_{2} 1$, $\mathrm{MgSO}_{4}$ 0.8, $\mathrm{CaCl}_{2}$ 2, glucose 5, Hepes 10, pH 7.4.

Microscopic determinations of fura-2 fluorescence were performed with a standard photometric setup (model MSP 21; Zeiss, Oberkochen, Germany) assisted by a microcomputer. For each tubular sample, the portion selected for fluorescence measurements was centered across a circular field diaphragm (60 $\mu \mathrm{m}$ diameter) including $\sim 20-30$ cells. Fluorescence intensities were recorded for two excitation wavelengths, 340 and $380 \mathrm{~nm}$. Tubule autofluorescence at the two wavelengths was determined on homologous segments not loaded with fura-2 and superfused as described above. For each tubule, the net fluorescence intensities of fura-2 at $340(\mathrm{~S})$ and $380 \mathrm{~nm}(\mathrm{~L})$ were obtained by subtracting the corresponding autofluorescence from all measurements. $[\mathrm{Ca}]_{i}$ was calculated from the ratio (R) of $\mathrm{S}$ and $\mathrm{L}$ according to the following equation:

$[\mathrm{Ca}]_{\mathrm{i}}=K_{\mathrm{d}} \times \frac{(\mathrm{R}-\mathrm{Rmin})}{(\mathrm{Rmax}-\mathrm{R})} \times \lambda$,

where $K_{\mathrm{d}}(224 \mathrm{nM})$ is the dissociation constant of fura- 2 for calcium; $R \min$ and $R \max$ are the values of $R$ at 0 and saturating calcium concentrations, respectively; and $\lambda(\mathrm{Lmax} / \mathrm{Lmin})$ is the ratio of $\mathrm{L}$ at 0 and saturating calcium concentrations.

Cyclic GMP and cyclic AMP content. Cyclic GMP and cyclic AMP content were determined by radioimmunoassay in microdissected tubular segments, following a procedure first described by Chabardes et al. (14). 29 (13 for cyclic GMP and 16 for cyclic AMP) male Swiss white mice were anesthetized with sodium pentobarbital $(0.1 \mathrm{mg} / 10 \mathrm{~g}$ body wt). The left kidney was perfused in situ via the abdominal aorta with $5 \mathrm{ml}$ of incubation solution containing (mM), for cyclic GMP: $\mathrm{NaCl}$ $120, \mathrm{KCl} 5, \mathrm{CaCl}_{2} 1, \mathrm{MgSO}_{4} 1, \mathrm{NaH}_{2} \mathrm{PO}_{4} 4, \mathrm{NaHCO}_{3} 4$, glucose 5, lactate 10 , pyruvate 1 , arginine 0.8 , and Hepes 20 . The incubation solution was similar for cyclic AMP, except that lactate, pyruvate, and arginine were omitted and replaced by $\mathrm{CH}_{3} \mathrm{COONa} 10 \mathrm{mM}{ }^{2}$ Dextran $40,000(0.3 \% \mathrm{wt} / \mathrm{vol})$, collagenase $(151 \mathrm{U} / \mathrm{mg}) 0.3 \% \mathrm{wt} / \mathrm{vol}$, and bovine serum albumin $0.1 \% \mathrm{wt} / \mathrm{vol}$ were added. The left kidney was removed, and thin pyramids were then cut out along the corticopapillary axis of the kidney and were incubated for $10-15 \mathrm{~min}$ at $35^{\circ} \mathrm{C}$ in the incubation solution containing $0.1 \%$ collagenase. cTALs, mTALs, and medullary collecting tubules were microdissected from the cortex and the inner stripe of the outer medulla, respectively. The length of the tubules was determined with an ocular micrometer.

For cyclic GMP determination, a pool of tubular segments (20-30 $\mathrm{mm}$ for each point) was transferred into a tube containing $10 \mu$ l incubation solution added with $10^{-3} \mathrm{M}$ 3-isobutyl-1-methylxanthine. Each sample was preincubated for $15 \mathrm{~min}$ at $35^{\circ} \mathrm{C}$ and then was incubated for $10 \mathrm{~min}$ at $35^{\circ} \mathrm{C}$ in the presence of $10 \mu \mathrm{l}$ of either the solution alone (basis), PAF $\left(10^{-7} \mathrm{M}\right)$, or PAF $\left(10^{-7} \mathrm{M}\right)$ plus BN $50730\left(10^{-6} \mathrm{M}\right)$. The reaction was stopped with $200 \mu \mathrm{l}$ of a mixture of formic acid in absolute ethanol $(10 \% \mathrm{vol} / \mathrm{vol})$, at $4^{\circ} \mathrm{C}$. After evaporation, acetate buffer was added, and cyclic GMP was determined by radioimmunoassay after acetylation. The limit of detection was $3 \mathrm{fmol}$ of cyclic GMP per tube.

For cyclic AMP determination, one or two tubular segments were transferred to a slide in $2 \mu \mathrm{l}$ of incubation solution added with $5 \times 10^{-6}$ M Ro 201724, an inhibitor of the high affinity cyclic AMP phosphodiesterase (type IV). Each sample was preincubated for $10 \mathrm{~min}$ at $35^{\circ} \mathrm{C}$ and then incubated for $4 \mathrm{~min}$ at $35^{\circ} \mathrm{C}$ in the presence of $2 \mu \mathrm{l}$ of either the solution alone (basis) or the required hormone. The reaction was stopped by transferring the tubular sample $(1 \mu \mathrm{l})$ into a tube containing $25 \mu \mathrm{l}$ of a mixture of formic acid in absolute ethanol $(10 \% \mathrm{vol} / \mathrm{vol})$. After evaporation, acetate buffer was added, and cyclic AMP was determined by radioimmunoassay after acetylation. The limit of detection was 1 fmol of cyclic AMP per tube.

For cyclic AMP, five to seven replicates per condition were pooled and considered as one point. For cGMP, a single assay was tested per condition. Values were expressed as means $\pm \mathrm{SE}$. Statistical significance was evaluated by the paired Student's $t$ test when two conditions were tested in the same series (cyclic GMP) and by the one-way analysis of variance followed by the Fischer's least significant difference test when more than two conditions were tested in the same series (cyclic AMP).

Materials. PAF was purchased from Eurobio (Paris, France), $N$-[2(methylamino)-ethyl]-5-isoquinoline-sulfonamide (H-8) from Research Biochemicals Inc. (Natick, MA), collagenase CLS II from Worthington Biochemical Corp. (Freehold, NJ), BAPTA/AM and ionomycin from Calbiochem-Novabiochem (La Jolla, CA). BN 50730 was a gift from Beaufour (Les Ulis, France), and Ro 201724 from Hoffman-La Roche (Basel, Switzerland). Cyclic AMP and cyclic GMP antibodies were

2. Substrates were added in the cGMP medium in order to use proximal tubules and glomeruli as well, when necessary. 


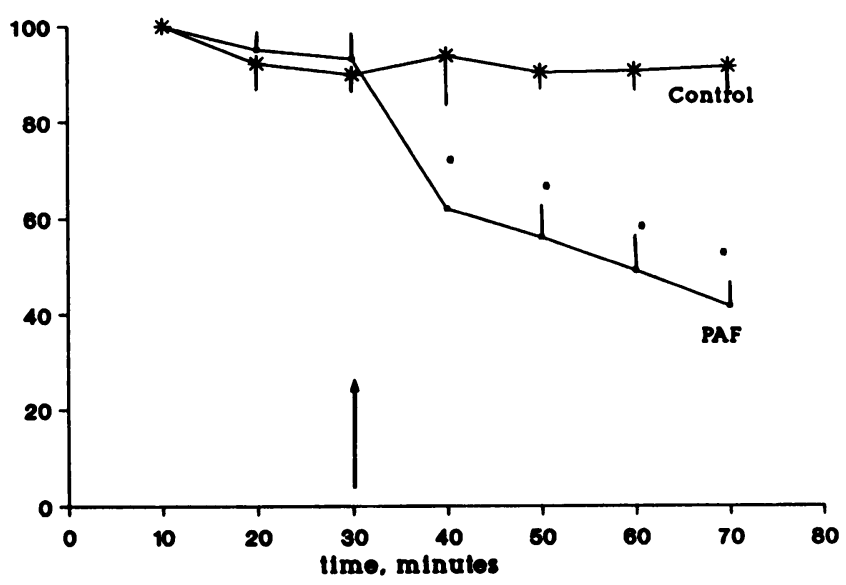

Figure 1. Evolution with time of net chloride reabsorption $\left(\mathrm{J}_{\mathrm{Cl}}\right)$ in the cTAL. $\mathrm{J}_{\mathrm{Cl}}$ was expressed as a percentage of the first value (vertical axis) (mean of the first $\mathrm{J}_{\mathrm{Cl}}$ value: $72.4 \pm 11.1, n=4$, and 96.6 $\pm 4.4, n=5$, for control and PAF, respectively). The beginning of the first period was considered as zero time. At the time indicated by the arrow, PAF $10^{-7} \mathrm{M}$ was added to the bath. *Significantly different $(P<0.01)$ from the control.

obtained in unité INSERM 64 (Hôpital Tenon, Paris, France). All other compounds were purchased from Sigma Chemical Co. (St. Louis, MO).

\section{Results}

Effect of PAF on chloride reabsorption. In the cTAL, PAF $10^{-7} \mathrm{M}$ significantly decreased $\mathrm{J}_{\mathrm{Cl}}$ while this parameter was not significantly modified in time-control tubules (Fig. 1). In the presence of PAF, indeed, $\mathrm{J}_{\mathrm{Cl}}$ was decreased from $92.9 \pm 4.8$ $\mathrm{pmol} / \mathrm{min}$ in the control period (mean values from time 0 to 30 $\mathrm{min}$ ) to $46.5 \pm 6.7 \mathrm{pmol} / \mathrm{min}$ in the experimental period (mean values from time 40 to $70 \mathrm{~min}, P<0.01$, Table I).

Role of protein kinase $C$. The presence throughout the experiment of $10^{-7} \mathrm{M}$ staurosporine, a protein kinase $\mathrm{C}$ inhibitor, did not prevent the inhibition of $\mathrm{J}_{\mathrm{Cl}}$ by PAF (Fig. 2). Moreover, administration during the experimental period of $10^{-8}-10^{-7} \mathrm{M}$ PMA, a protein kinase $\mathrm{C}$ activator, failed to mimick the inhibi-

Table I. Absence of Additivity between PAF and 8-Bromo cGMP on Chloride Reabsorption in the cTAL

\begin{tabular}{lcccc}
\hline & $\begin{array}{c}\text { Number of } \\
\text { tubules }\end{array}$ & $v$ & $\Delta \mathrm{Cl}$ & $\mathrm{J}_{\mathrm{Cl}}$ \\
\hline & & $n V / \min$ & $m M$ & $p m o / / \min$ \\
$\mathrm{C}$ & 5 & $5.2 \pm 0.7$ & $19.3 \pm 2.5$ & $92.9 \pm 4.8$ \\
$\mathrm{E}(\mathrm{PAF})$ & & $5.3 \pm 0.7$ & $9.9 \pm 2.3^{*}$ & $46.5 \pm 6.7^{*}$ \\
$\mathrm{C}$ & 8 & $5.6 \pm 1.0$ & $16.3 \pm 5.7$ & $69.5 \pm 12.6$ \\
$\mathrm{E}(8 \mathrm{BrcG})$ & & $5.5 \pm 0.9$ & $9.1 \pm 3.0^{\ddagger}$ & $42.1 \pm 9.2^{*}$ \\
$\mathrm{C}$ & 4 & $4.0 \pm 1.2$ & $31.1 \pm 9.5$ & $96.6 \pm 12.5$ \\
$\mathrm{E}(8 \mathrm{BrcG}+\mathrm{PAF})$ & & $3.7 \pm 1.0$ & $19.7 \pm 4.9$ & $61.1 \pm 10.0^{*}$ \\
& & & &
\end{tabular}

Values are means $\pm \mathrm{SE}$. $\Delta \mathrm{Cl}$, chloride concentration difference between the perfused and the collected fluid; $\mathrm{J}_{\mathrm{Cl}}$, net chloride reabsorption; $\mathrm{C}$, control period; E, experimental period; PAF, $10^{-7} \mathrm{M}$; $8 \mathrm{BrcG}$, 8-bromo cyclic GMP $5.10^{-5} \mathrm{M} . \quad{ }^{\ddagger} P<0.001,{ }^{*} P<0.01$ versus the control value.

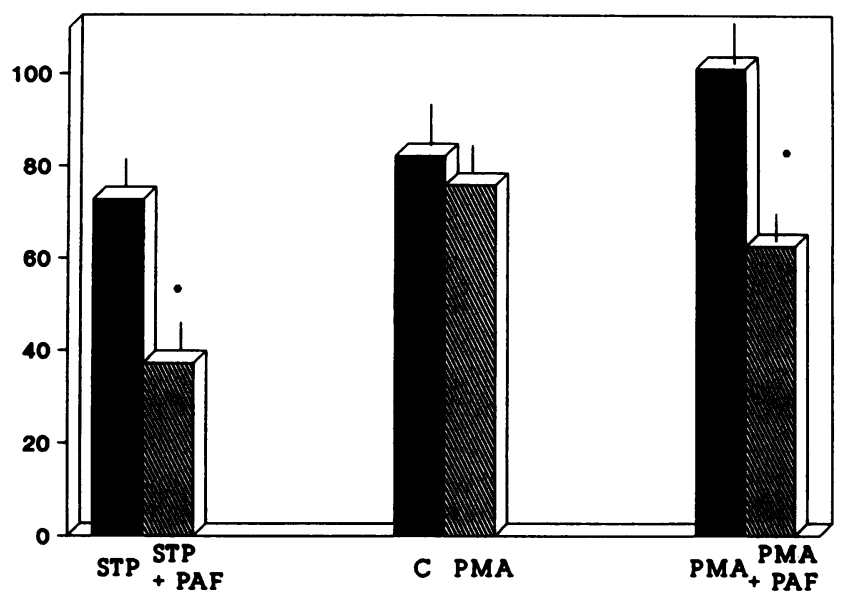

Figure 2. Role of protein kinase $\mathrm{C}$ in the effect of PAF on chloride reabsorption $\left(\mathrm{J}_{\mathrm{Cl}}\right.$ in $\mathrm{pmol} / \mathrm{min}$, vertical axis) in the cTAL. Control period, black columns; experimental period, hatched columns. STP, staurosporine, $10^{-7} \mathrm{M} ; P M A$, phorbol 12 -myristate 13 -acetate, $10^{-8}-10^{-7} \mathrm{M}$; $P A F$ : platelet-activating factor, $10^{-7}$ M. *Significantly different $(P<$ 0.01 ) from the control period; $n=5$ for each group.

tory effect of PAF on $\mathrm{J}_{\mathrm{Cl}}$. Finally, the presence of PMA throughout the experiment did not prevent the effect of PAF (Fig. 2).

$P A F$ effect on intracellular calcium. When $[\mathrm{Ca}]_{i}$ was determined in isolated cTALs, PAF $10^{-7} \mathrm{M}$ induced a trivial increase in this parameter $\left(\Delta[\mathrm{Ca}]_{\mathrm{i}}: 9.7 \pm 2.9 \mathrm{nM}, n=22\right)$ by comparison with $10^{-8} \mathrm{M}$ angiotensin II $\left(\Delta[\mathrm{Ca}]_{\mathrm{i}}: 69.2 \pm 17.7 \mathrm{nM}, n=9\right.$, Fig. 3). When tested on the same tubule, $10^{-7} \mathrm{M}$ Lyso-PAF elicited a similar effect as PAF $\left(\Delta[\mathrm{Ca}]_{\mathrm{i}}: 3.9 \pm 3.0\right.$ and $5.6 \pm 3.7 \mathrm{nM}$ for PAF and Lyso-PAF, respectively, $n=8$ ). However, the signal observed with angiotensin II was highly variable in the cTAL (from 13 to $150 \mathrm{nM}$ ), as well as in the mTAL (data not shown). Similar experiments have thus been performed in the rat mTAL, in which angiotensin $\mathrm{II}$ induced a reproducible increase in $[\mathrm{Ca}]_{\mathrm{i}}$ $\left(\Delta[\mathrm{Ca}]_{\mathrm{i}}: 142.8 \pm 13.4 \mathrm{nM}, n=6\right)$. In the rat mTAL, as well as in the mouse cTAL, PAF did not increase $[\mathrm{Ca}]_{\mathrm{i}}:\left(\Delta[\mathrm{Ca}]_{\mathrm{i}}\right.$ : $15.2 \pm 10.2 \mathrm{nM}, n=6$ ) while it decreased $\mathrm{J}_{\mathrm{Cl}}$, as checked on two microperfused tubules.

Chelating cytosolic calcium by $10^{-5} \mathrm{M}$ BAPTA/AM failed to prevent the PAF-induced decrease of $\mathrm{J}_{\mathrm{Cl}}$ (Fig. 4). Nevertheless, the same maneuver completely blocked the inhibitory ef-

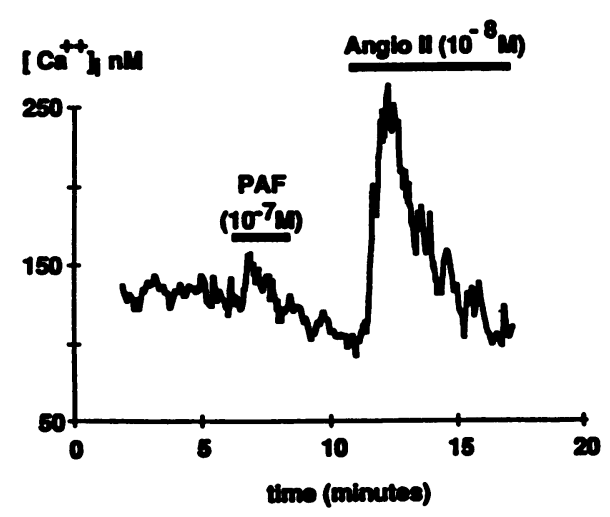

Figure 3. Recording from one experiment of intracellular calcium concentration determination (ordinate) in the presence of PAF and angiotensin II (Angio II), in the mouse cTAL. 


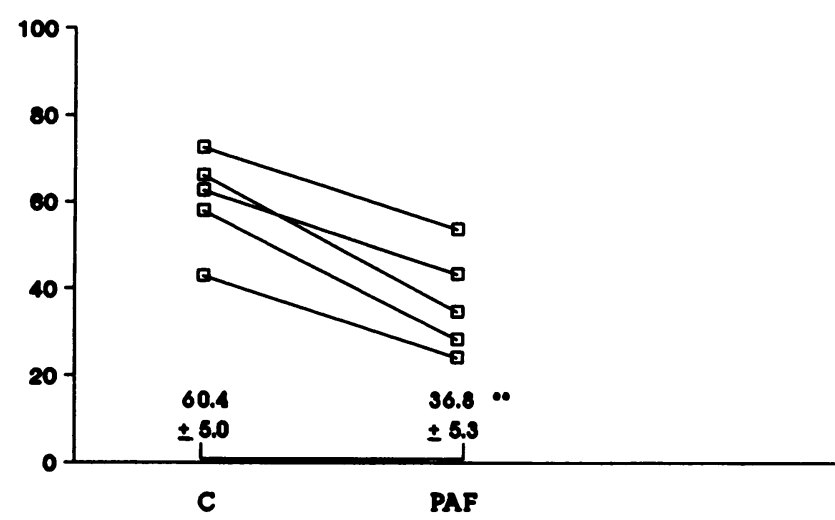

Figure 4. Effect of PAF on chloride reabsorption $\left(\mathrm{J}_{\mathrm{Cl}}\right.$ in $\mathrm{pmol} / \mathrm{min}$, vertical axis) in individual cTALs pretreated with BAPTA/AM. Tubules were loaded with BAPTA/AM $10^{-5} \mathrm{M}$ half an hour before the beginning of the control period (C). PAF $10^{-7} \mathrm{M}$ was added to the bath in the experimental period.

fect on $\mathrm{J}_{\mathrm{Cl}}$ of a Ca ionophore $\left(10^{-7} \mathrm{M}\right)$, ionomycin or $\mathrm{A}_{23187}$ (24.8 $\pm 2.8 \%$ inhibition, $n=5$ vs $4.6 \pm 2.6 \%, n=3, P<0.01$, without and with BAPTA/AM pretreatment, respectively). Moreover, it was verified that $10^{-5} \mathrm{M}$ BAPTA/AM abolished the $[\mathrm{Ca}]_{i}$ peak induced by angiotensin II, in the rat mTAL $\left(\Delta[\mathrm{Ca}]_{\mathrm{i}}, \mathrm{nM}: 136.7 \pm 22.4, n=6\right.$ vs $6.2 \pm 1.2, n=6, P<0.001$, in the absence and in the presence of BAPTA, respectively).

Role of cyclic GMP. The inhibitory effect of PAF on $\mathrm{J}_{\mathrm{Cl}}$ was mimicked by $10^{-4} \mathrm{M}$ 8-bromo cyclic GMP (Table I and Fig. 5). Simultaneous addition of PAF and 8-bromo cyclic GMP in the experimental period did not decrease $\mathrm{J}_{\mathrm{Cl}}$ to a further extent than each agent alone $(50.3 \pm 6.5,39.6 \pm 5.2$, and $37.7 \pm 2.7 \%$ inhibition for PAF, 8-bromo cyclic GMP, and PAF plus 8bromo cyclic GMP, respectively, NS, Table I). Moreover, on the same tubule, previous administration of 8-bromo cyclic GMP prevented a further decrease of $\mathrm{J}_{\mathrm{Cl}}$ by PAF (Fig. 5).

To investigate whether the PAF effect on $\mathrm{J}_{\mathrm{Cl}}$ required a cyclic GMP-dependent protein kinase activation, experiments

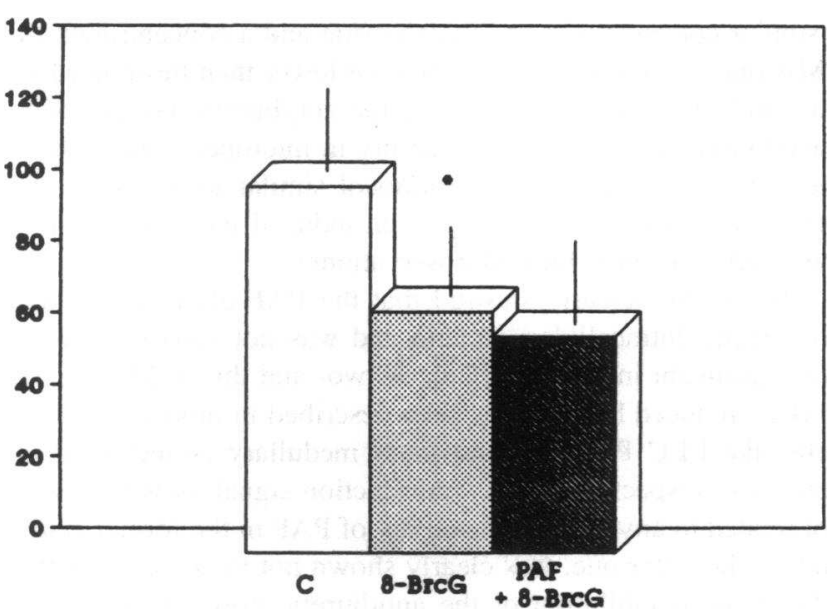

Figure 5. Absence of PAF effect on chloride reabsorption $\left(\mathrm{J}_{\mathrm{Cl}}\right.$ in pmol/ min, vertical axis) in the presence of 8-bromo cyclic GMP (8-BrCG). After the control period (C), 8-BrcG $10^{-4} \mathrm{M}$ was added to the bath; PAF $10^{-7} \mathrm{M}$ was further added to the bath, always in the presence of 8 -BrcG. *Significantly different $(P<0.01)$ from the preceeding period; $n=6$.
Table II. Effect of PAF on Chloride Reabsorption in the Presence of $H-8$, in the cTAL

\begin{tabular}{lccc}
\hline & $v$ & $\Delta \mathrm{Cl}$ & $\mathrm{J}_{\mathrm{Cl}}$ \\
\hline & $n V_{\text {min }}$ & $m M$ & $p \operatorname{mol} / \min$ \\
$\mathrm{C}(\mathrm{H}-8)$ & $5.9 \pm 1.2$ & $10.7 \pm 1.9$ & $58.7 \pm 9.7$ \\
$\mathrm{E}(\mathrm{H}-8+\mathrm{PAF})$ & $5.8 \pm 1.4$ & $10.0 \pm 2.1$ & $51.3 \pm 6.7$ \\
\hline
\end{tabular}

Values are means \pm SE. For abbreviations see Table I. PAF, $10^{-7} \mathrm{M} ; \mathrm{H}-$ $8, N$-[2-(methylamino)-ethyl]-5-isoquinoline-sulfonamide, $10^{-6} \mathrm{M}$. Four tubules were tested.

have been performed in the presence of $\mathrm{H}-8$, a protein kinase inhibitor more selective for the cyclic GMP than for the cyclic AMP-dependent enzyme. As already reported (15), it was verified that $\mathrm{H}-8,10^{-6} \mathrm{M}$ in the bath, did not significantly modify $\mathrm{J}_{\mathrm{Cl}}(60.5 \pm 10.1$ vs $66.0 \pm 10.2 \mathrm{pmol} / \mathrm{min}, n=10)$. The presence of this agent completely abolished the inhibitory effect of PAF on $\mathrm{J}_{\mathrm{Cl}}$ (Table II).

Cyclic GMP content was determined on isolated mTALs in two series of experiments. In the first one, PAF significantly increased this parameter over the basal values by about twofold, and, in the other one, the PAF-induced increase in cGMP content was significantly reduced in the presence of the PAF antagonist BN 50730 (Fig. 6). Since an effect of PAF on the transepithelial resistance was recently described in cultured medullary collecting tubules cells (16), cyclic GMP content was determined in medullary collecting tubules as well; no difference was observed in cyclic GMP content between PAF alone $(2.82 \pm 1.32$ $\mathrm{fmol} / 10 \mathrm{~min}$ per $\mathrm{mm}$ ) and PAF plus BN 50730 (2.18 0.97 fmol/10 min per $\mathrm{mm}, \mathrm{NS}, n=6$ ).

Effect of PAF on cAMP content. Since cyclic AMP content may be modulated by cyclic GMP-dependent phosphodiesterase, a possible effect of PAF on cyclic AMP content was tested in isolated mTALs and cTALs (Table III). In the presence of Ro 201724, PAF did not significantly modify cyclic AMP content either in basal or stimulated conditions, in both segments.

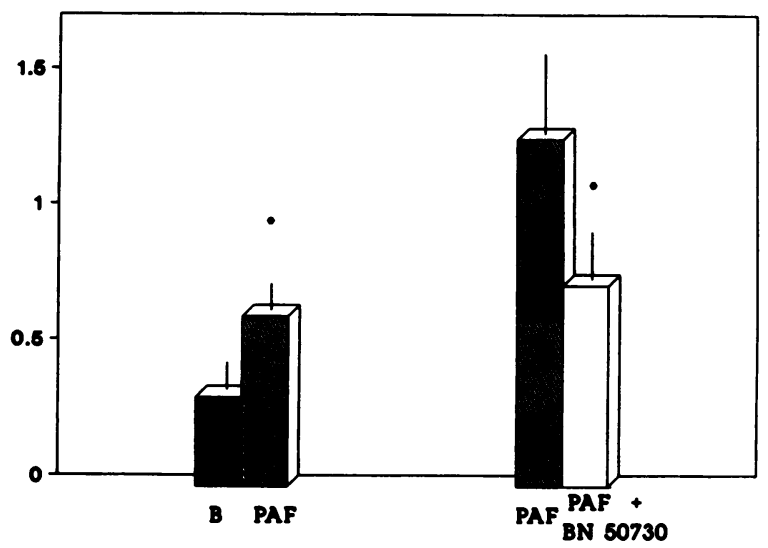

Figure 6. Cyclic GMP (cGMP in $\mathrm{fmol} / \mathrm{mm}$ per $10 \mathrm{~min}$, vertical axis) content in isolated mTALs from mouse kidney. Each determination has been performed on a $20-30-\mathrm{mm}$ tubular segment. Experiments have been performed in two paired series: in one (left, $n=8$ ), the effect of PAF $\left(10^{-7} \mathrm{M}\right)$ was compared to basal values $(B)$; in the other one (right, $n=5)$, the effect of PAF in the presence of BN $50730\left(10^{-6} \mathrm{M}\right)$ was compared with the effect of PAF alone. $*$ Significantly different $(P$ $<0.05$ ) from basal (left) or PAF (right) values. 
Table III. Cyclic AMP Content on Isolated mTALs and cTALs

\begin{tabular}{lcc}
\hline & \multicolumn{2}{c}{ cAMP content (fmol/4 min per mm) } \\
\cline { 2 - 3 } & $\begin{array}{cc}\text { mTAL } \\
(8)\end{array}$ & $\begin{array}{c}\text { cTAL } \\
(9)\end{array}$ \\
\hline Basis & $1.7 \pm 0.3$ & $2.1 \pm 0.8$ \\
PAF & $1.9 \pm 0.3$ & $2.9 \pm 1.2$ \\
Hormone & $11.1 \pm 3.3^{*}$ & $13.3 \pm 3.0^{\ddagger}$ \\
Hormone + PAF & $7.3 \pm 2.0^{\xi} \|$ & $10.4 \pm 2.8^{*} \|$
\end{tabular}

Values are means \pm SE. $n$, number of mice. For each experiment, five to seven tubules per condition were tested. PAF, $10^{-7} \mathrm{M}$; Hormone, either parathyroid hormone, $10^{-8} \mathrm{M}$ (3 cTALs), glucagon $10^{-8} \mathrm{M}(6$ cTALs, 3 mTALs), or antidiuretic hormone $10^{-8} \mathrm{M}(5 \mathrm{mTAL}){ }^{8} P$ $<0.05,{ }^{*} P<0.01,{ }^{\ddagger} P<0.001$ versus the basal value. "NS versus hormone.

The absence of statistical significance of the slight difference in the means between hormone and hormone plus PAF did not likely result from a too low number of experiments. No significance was reached, indeed, when the data from cTAL and mTAL were pooled $(t=1.6)$.

Role of nitric oxide (NO) synthase. In the cTAL, sodium nitroprusside significantly decreased $\mathrm{J}_{\mathrm{Cl}}$ (Table IV), suggesting the presence of a soluble guanylate cyclase activity in this segment. To investigate a possible activation of this enzyme by PAF through NO production, experiments have been performed in the presence of two NO synthase inhibitors, $N^{G}$-nitro-L-arginine methyl ester (NAME) or $N$ mono methyl arginine (NMMA). Administration of each of these agents, $10^{-4} \mathrm{M}$ in the bath, throughout the experiment failed to impair the inhibitory effect of PAF on $\mathrm{J}_{\mathrm{Cl}}(32.8 \pm 4.6$ vs $52.8 \pm 6.2 \mathrm{pmol} / \mathrm{min}$, in the experimental and control period, respectively, $n=7, P$ $<0.001$, Fig. 7). Moreover, it was verified that the presence of NAME did not significantly modify $\mathrm{J}_{\mathrm{Cl}}(53.3 \pm 7.7$ vs $55.8 \pm 8.2$ $\mathrm{pmol} / \mathrm{min}$, with and without this agent, respectively, $n=5$ ).

\section{Discussion}

This study was undertaken to investigate the signaling pathway involved in the PAF-induced decrease of $\mathrm{J}_{\mathrm{Cl}}$ in the thick ascending limb of Henle's loop. In a previous work (2), it was shown that this effect was not mediated either by arachidonic acid metabolites or by adenosine. The present results further indicate that, at variance with what was reported in other target cells (5), the inhibition by PAF of $J_{\mathrm{Cl}}$ in the cTAL did not involve protein kinase $\mathrm{C}$, was not associated with any $[\mathrm{Ca}]_{i}$

Table IV. Effect of Sodium Nitroprusside on Chloride Reabsorption in the cTAL

\begin{tabular}{|c|c|c|c|}
\hline & $\boldsymbol{V}$ & $\Delta \mathrm{Cl}$ & $\mathbf{J}_{\mathrm{C}}$ \\
\hline & $n V / m m$ & $m M$ & pmol/min \\
\hline $\mathrm{C}$ & $3.4 \pm 0.9$ & $24.6 \pm 6.1$ & $57.8 \pm 6.3$ \\
\hline $\mathrm{E}(\mathrm{SNP})$ & $3.4 \pm 0.9$ & $13.4 \pm 3.5 *$ & $35.4 \pm 5.0^{\ddagger}$ \\
\hline
\end{tabular}

Values are means \pm SE. For abbreviations, see Table I. SNP, sodium nitroprusside $10^{-3} \mathrm{M}$. Seven tubules were tested. ${ }^{\ddagger} P<0.001, \quad * P$ $<0.01$ versus the control value.

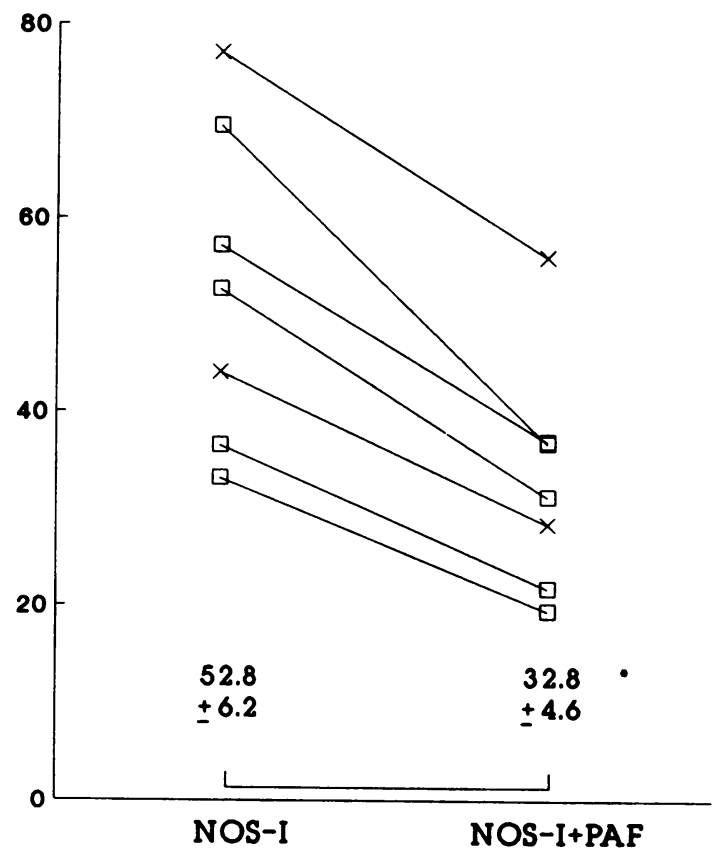

Figure 7. Effect of PAF on chloride reabsorption $\left(\mathrm{J}_{\mathrm{Cl}}\right.$ in $\mathrm{pmol} / \mathrm{min}$, vertical axis) in individual cTALs in the presence of NO synthase inhibitors (NOS-I), either NAME (square) or NMMA (cross). $10^{-4} \mathrm{M}$ NO synthase inhibitor was present in the bath since the control period. PAF $10^{-7} \mathrm{M}$ was added in the experimental period. *Significantly different $(P<0.01)$ from the NO synthase inhibitor alone.

increase, did not modify cyclic AMP content, but was mediated by cyclic GMP. Moreover, it was strongly suggested that this effect of PAF was not related to an NO synthesis.

Absence of role of protein kinase $C$ and intracellular calcium. The present data strongly suggested that protein kinase $\mathrm{C}$ was not involved in the inhibitory effect of PAF on $\mathrm{J}_{\mathrm{Cl}}$ since the latter was not modified by the stimulation or by the inhibition of the enzyme activity. The absence of effect of staurosporine and PMA observed in this study likely did not result from the use of too low concentrations of the agents since (a) a similar concentration of staurosporine and a concentration of PMA one or two orders of magnitude lower than those used in this study were able to modulate the antidiuretic hormone-induced increase in water permeability in microperfused collecting tubule (17), and $(b)$ in a protocol similar to that reported here, PMA did inhibit the glucagon-induced increase in $\mathrm{J}_{\mathrm{Cl}}$ in the cTAL (our unpublished observations).

The results clearly showed that the PAF effect on $\mathrm{J}_{\mathrm{Cl}}$ did not require intracellular calcium and was not associated with any significant increase in [Ca $]_{i}$. A two- and threefold increase in $[\mathrm{Ca}]_{\mathrm{i}}$ induced by PAF has been described in tubular cultured cells like $L L C \mathrm{PK}_{1}(18)$ and inner medullary collecting duct cells (16), respectively. This transduction signal, however, was not related to any biological activity of PAF in the former study and, in the latter one, was clearly shown not to account for the PAF-induced inhibition of the antidiuretic hormone effect on the transepithelial resistance.

These results, associated with our previous work showing that the effect of PAF on $\mathrm{J}_{\mathrm{Cl}}$ was not mediated by arachidonic acid metabolites (2), strongly argue for an absence of involvement of a PAF-stimulated phospholipid turnover in the effect reported here. 
Role of cyclic GMP. Several lines of evidence suggested that cyclic GMP mediated the PAF-induced decrease of $\mathrm{J}_{\mathrm{Cl}}$ since, firstly, this effect in the cTALs was mimicked by 8bromo cyclic GMP analogue, was not additive with the effect of the analogue, was inhibited by a cyclic GMP-dependent protein kinase inhibitor (H-8), and since, secondly, PAF significantly increased cyclic GMP content in mTALs. Similar results have been obtained previously in our laboratory (15) with the atrial natriuretic factor, which is known to activate guanylate-cyclase. As discussed elsewhere (15), one can question the selectivity of $\mathrm{H}-8$ on the cyclic GMP-dependent protein kinase. The fact that, in the same work, staurosporine, another protein kinase inhibitor more selective for the protein kinase $\mathrm{C}$ than for the cyclic GMP-dependent enzyme, failed to abolish the effect of PAF on $\mathrm{J}_{\mathrm{Cl}}$ strongly argues, in the results presented here, for a specific enough effect of $\mathrm{H}-8$ on the cyclic GMPdependent protein kinase.

In regard to cyclic GMP content in microdissected mTALs, the basal and stimulated values reported here and by others $(12,15,19)$ were low as compared with the cyclic AMP ones. Nevertheless, the cyclic GMP content in the presence of PAF was similar to those obtained by Nonoguchi et al. $(12,19)$ with atrial natriuretic factor or by Koike et al. (20) with urodilatin, both hormones exhibiting an effect on $\mathrm{J}_{\mathrm{Cl}}$ similar to that of PAF $(12,15)$.

The question was to be raised whether the PAF-induced inhibition of $\mathrm{J}_{\mathrm{Cl}}$ resulted from a cyclic GMP-mediated decrease of cyclic AMP content. The present data indicated that, in the presence of a partial inhibition of phosphodiesterase activity, PAF did not significantly modify cyclic AMP content in the TAL. Moreover, this result was in agreement with our previous study showing that the effect of PAF on $\mathrm{J}_{\mathrm{Cl}}$ was similar whether isoproterenol was present or not (2). Conversely to PAF, $\mathrm{PGE}_{2}$, which has been described to inhibit chloride reabsorption in the mTAL, in the presence of vasopressin but not in basal conditions (21), exhibited an $80 \%$ inhibition of the vasopressin-induced increase in cAMP content, in the rat and mouse mTAL (reference 22, and our unpublished observation). Moreover, the present results indicated that the mechanism of PAF action in the TAL was different from the one reported in platelets, in which PAF induced a $95 \%$ inhibition on the $\mathrm{PGE}_{1}$-increased cAMP content (23). Finally, the absence of interaction between PAF and cyclic AMP allowed us to exclude a possible increase in cyclic GMP content mediated by the PAF-stimulated cyclic AMP production, as reported in bacteria (24).

Absence of PAF effect on NO synthesis. Evidence exists that the PAF-induced increase in cyclic GMP did not result from a stimulation of NO synthase. First, two different NO synthase inhibitors, at a concentration usually used (25), failed to abolish the effect of PAF on $J_{\mathrm{Cl}}$ in this study. Second, recent reports $(26,27)$ have detected in the cTAL and MTAL an inducible but not constitutive NO synthase. The short delay for the response to PAF of $\mathrm{J}_{\mathrm{Cl}}$ (Fig. 1) as well as transepithelial voltage (2) is against a possible induction of NO synthase by PAF in this segment. It must be noted, however, that the present results did not bring any evidence for effectiviness of the NO synthase inhibitors in the conditions used here. The absence in TAL of a constitutive NO synthase and the fact that, to this date, no effect of NO synthase activation on TAL transport is available rendered such a control uneasy. Cyclic GMP has been described to be involved in the vasodilatory action of PAF on the renal afferent arteriole (28). This effect, however, resulted from an activation by PAF of the endothelial, calcium-stimulated NO synthase.

The results presented here thus raise the question of the mechanism of action of PAF on the cyclic GMP production. On the one hand, a PAF receptor cloned from human heart (29) was described to belong to the rhodopsin-type receptor family, suggesting a PAF action on the phosphodiesterase activity rather than on a membranous guanylate cyclase. On the other hand, the fact that, in this work, PAF increased cyclic GMP content in the presence of a nonspecific phosphodiesterase blocker a priori allowed us to rule out a possible inhibition by PAF of this enzyme activity. Other investigations are needed to further elucidate the signal involved in the PAF-induced increase in cyclic GMP production.

In conclusion, the present paper showed that the PAF-induced decrease of $\mathrm{J}_{\mathrm{Cl}}$ in the TAL is mediated by cyclic GMP, independent of NO production, indicating that PAF exerted its action on the TAL reabsorptive function through a signaling pathway different from that involved in its glomerular effects.

\section{Acknowledgments}

The authors are indebted to Pr. Claude Amiel for his helpful discussions. The technical assistance of Sylviane Couette and Marie Teixeira and the secretarial assistance of Josseline Nicolet are gratefully acknowledged.

This work was supported by grants from Institut National de la Santé et de la Recherche Médicale, Centre National de la Recherche Scientifique, Université Paris 7, and Fondation pour la Recherche Médicale.

\section{References}

1. Koltai, M., D. Hosford, P. Guinot, A. Esanu, and P. Braquet. 1991. PAF. A review of its effects, antagonists and possible future clinical implications. Drugs. 42:174-204.

2. Bailly, C., C. Barlet-Bas, and C. Amiel. 1992. Platelet activating factor inhibits $\mathrm{Cl}$ and $\mathrm{K}$ transport in the medullary thick ascending limb. Kidney Int. 41:269-274.

3. Schlondorff, D., and R. Neuwirth. 1986. Platelet-activating factor and the kidney. Am. J. Physiol. 251:F1-F11.

4. Brezis, M., S. Rosen, P. Silva, and F. H. Epstein. 1984. Renal ischemia: a new perspective. Kidney Int. 26:375-383.

5. Shukla, S. D. 1992. Platelet-activating factor receptor and signal transduction mechanisms. FASEB (Fed. Am. Soc. Exp. Biol.) J. 6:2296-2301.

6. Kester, M., C. P. Thomas, J. Wang, and H. J. Dunn. 1992. Platelet-activating factor stimulates multiple signaling pathways in cultured rat mesangial cells. $J$. Cell. Physiol. 153:244-255.

7. Takano, T., Z. Honda, T. Watanabe, S. Uchida, T. Shimizu, and K. Kurokawa. 1991. Demonstration of platelet activating factor receptor in guinea pig kidney. Biochem. Biophys. Res. Commun. 177:54-60.

8. Hebert, S. C., P. A. Friedman, and T. E. Andreoli. 1984. Effects of antidiuretic hormone on cellular conductive pathways in mouse medullary thick ascending limbs of Henle. I ADH increases transcellular conductance pathways. J. Membr. Biol. 80:201-219.

9. Di Stefano, A., N. Roinel, C. de Rouffignac, and M. Wittner. 1993. Transepithelial $\mathrm{Ca}^{2+}$ and $\mathrm{Mg}^{2+}$ transport in the cortical thick ascending limb of Henle's loop of the mouse is a voltage-dependent process. Renal Physiol. Biochem. 16:157-166.

10. Burg, M. B., J. J. Grantham, M. Abramow, and J. Orloff. 1966. Preparation and study of fragments of single rabbit nephrons. Am. J. Physiol. 210:1293-1298.

11. Ramsay, J. A., R. M. J. Brown, and P. C. Croghan. 1955. Electrometric titration of chloride on small volumes. J. Exp. Biol. 32:822-829.

12. Nonoguchi, H., K. Tomita, and F. Marumo. 1992. Effects of atrial natriuretic peptide and vasopressin on chloride transport in long- and short-looped medullary thick ascending limbs. J. Clin. Invest. 90:349-357.

13. Champigneulle, A., E. Siga, G. Vassent, and M. Imbert-Teboul. 1993. V $2^{-}$ like vasopressin receptor mobilizes intracellular $\mathrm{Ca}^{2+}$ in rat medullary collecting tubules. Am. J. Physiol. 265:F35-F45.

14. Chabardes, D., M. Montegut, M. Mistaoui, D. Butlen, and F. Morel. 1987. Atrial natriuretic peptide effect on cGMP and cAMP contents in microdissected glomeruli and segments of the rat and rabbit nephrons. Pflueg. Arch. Eur. J. Physiol. 408:366-372. 
15. Neant, F., and C. Bailly. 1993. Luminal and intracellular cGMP inhibit the mTAL reabsorptive capacity through different pathways. Kidney Int. 44:741 746.

16. Kraut, J. A., D. M. Mishler, A. Aboolian, and G. T. Nagami. 1992. Plateletactivating factor attenuates the arginine vasopressin-induced fall of transepithelial resistance across inner medullary collecting duct monolayers. Miner. Electrolyte Metab. 18:9-14.

17. Ando, Y., H. R. Jacobson, and M. D. Breyer. 1988. Phorbol ester and A23187 have additive but mechanistically separate effects on vasopressin action in rabbit collecting tubule. J. Clin. Invest. 81:1578-1584.

18. Ueda, N., P. R. Mayeux, P. D. Walker, and S. V. Shah. 1991. Receptormediated increase in cytosolic calcium in LLC-PK $_{1}$ cells by platelet-activating factor and thromboxane A2. Kidney Int. 40:1075-1081.

19. Nonoguchi, H., M. A. Knepper, and V. C. Manganiello. 1987. Effects of atrial natriuretic factor on cyclic guanosine monophosphate and cyclic adenosine monophosphate accumulation in microdissected nephron segments from rats. $J$. Clin. Invest. 79:500-507.

20. Koike, J., H. Nonoguchi, Y. Terada, K. Tomita, and F. Marumo. 1993 Effect of urodilatin on cGMP accumulation in the kidney. J. Am. Soc. Nephrol. 3:1705-1709.

21. Culpepper, R. M., and T. E. Andreoli. 1983. Interactions among prostaglandin $\mathrm{E}_{2}$, antidiuretic hormone, and cyclic adenosine monophosphate in modulating $\mathrm{Cl}^{-}$absorption in single mouse medullary thick ascending limbs of Henle. J. Clin. Invest. 71:1588-1601.

22. Torikai, S., and K. Kurokawa. 1983. Effect of $\mathrm{PGE}_{2}$ on vasopressin- dependent cell cAMP in isolated single nephron segments. Am. J. Physiol. 245:F58-F66.

23. Haslam, R. J., and M. Vanderwel. 1982. Inhibition of platelet adenylate cyclase by $1-O$-alkyl-2- $O$-acetyl-sn-glyceryl-3-phosphorylcholine (platelet-activating factor). J. Biol. Chem. 257:6879-6885.

24. Sordano, C., E. Cristino, F. Bussolino, B. Wurster, and S. Bozzaro. 1993. Platelet activating factor modulates signal transduction in Dictyostelium. J. Cell Sci. 104:197-202.

25. Moore, P. K., D. A. Al-Swayeh, N. W. Chang, R. A. Evans, and A. Gibson. 1990. $L-N^{G}$-nitro arginine (L-NOARG), a novel L-arginine-reversible inhibitor of endothelium-dependent vasodilation in vitro. Br. J. Pharmacol. 99:408-410.

26. Morrissey, J., R. McCracken, H. Kaneto, M. Vehaskari, D. Montani, and S. Klahr. 1994. Location of an inducible nitric oxide synthase mRNA in the normal kidney. Kidney Int. 45:998-1005.

27. Terada, Y., K. Tomita, H. Nonoguchi, and F. Marumo. 1992. Polymerase chain reaction localization of constitutive nitric oxide synthase and soluble guanylate cyclase messanger RNAs in microdissected rat nephron segments. J. Clin. Invest. 90:659-665.

28. Juncos, L. A., Y. Ren, S. Arima, and S. Ito. 1993. Vasodilator and constrictor actions of platelet-activating factor in isolated microperfused afferent arteriole of the rabbit kidney. J. Clin. Invest. 91:1374-1379.

29. Ye, R. D., E. R. Prossnitz, A. Zou, and C. G. Cochrane. 1991. Characterization of a human cDNA that encodes a functional receptor for platelet activating factor. Biochem. Biophys. Res. Commun. 180:105-111. 